\title{
Development and Implementation of a New Hands-on Freshman Engineering Design Course that Promotes Inclusiveness and Retention (Work in Progress)
}

\section{Dr. Tracy Jane Puccinelli, University of Wisconsin, Madison}

In 2011, Puccinelli joined the Biomedical Engineering (BME) Department. As part of the BME design faculty, she works on curriculum development, as well as innovative approaches for teaching design. Puccinelli coordinates BME outreach, advising BME seniors as they develop interactive, hands-on activities for K-12 students that teach biomedical engineering concepts. Additionally, in 2012, she began teaching an introductory engineering course (Introduction to Engineering Design) to incoming freshmen in the College of Engineering. In 2014, Puccinelli became a coordinator for the Introduction to Engineering Design course, which had become a popular course with more than 900-1000 students enrolled per year. When the college restructured and ended all freshman engineering courses, Puccinelli proposed two new multi-disciplinary freshman engineering courses in 2015: A 2 credit hands-on design course, and a 1 credit seminar style course. The hands-on course is now required for half of the engineering college and the seminar informational course is now required for all engineering freshman. Puccinelli is coordinating and teaching both courses this academic year (2016/17).

\section{Ms. Carla Winsor, University of Wisconsin, Madison}

Carla Winsor is a graduate student and teaching assistant at the University of Wisconsin - Madison. She conducts research in Mechanical Engineering specializing in Solid Mechanics and Orthopedic Biomechanics. This spring, she began a teaching assistant appointment teaching Design of Machine Elements for Junior level students. Carla works to promote women in Mechanical Engineering and mentors high school students, encouraging them to pursue STEM majors. Her professional background includes: a Bachelor of Science in Mechanical Engineering, a Bachelor of Business Administration in Organizational Leadership, active duty service in the United States Coast Guard, a co-op at Sandia National Laboratories, and an externship at the Museum of Science and Industry. In May, she will graduate with a dual Masters in Engineering Mechanics and Mechanical Engineering, before continuing her PhD studies. 


\section{Development and Implementation of a New Hands-On Freshman Engineering Design Course that Promotes Inclusiveness and Retention--Work In Progress}

Introduction

It is widely acknowledged that the freshman engineering experience is a critical time with an opportunity to make students feel welcome and increase retention, particularly of underrepresented minorities including women. The University of Wisconsin-Madison has a long history of offering a variety of introductory multi-disciplinary freshman engineering courses. Our most popular course, Intro 160, was a 3 credit course with a hands-on client-based design lab and a seminar style lecture. Recently, our college has decided to end all centrally funded multi-disciplinary freshman engineering courses, primarily due to budget cuts, and charged departments with the task of developing and funding their own freshman engineering courses. We developed a new freshman multi-disciplinary hands-on design course to take the place of the most popular freshman engineering course, Intro 160.

Approximately half (about 525 engineering freshmen) of our engineering college departments (Biomedical Engineering (35\%); Undeclared Engineering (26\%); Civil and Environmental Engineering (14\%); Engineering Mechanics/Astronautics (9\%); Biological Systems Engineering (6\%); Engineering Physics (6\%); and Nuclear Engineering (5\%)) agreed to participate and fund a multi-disciplinary hands-on design course. Last year, we analyzed student retention data over the past three decades and correlated the data with the introduction to engineering course taken as freshmen. [1] Analysis of course-specific retention data did not clearly align with other research suggesting a positive relationship between hands-on design and retention of underrepresented minorities. [2-5] Thus, we plan to implement and assess changes to course structure and curriculum to determine best practices to create a more inclusive and welcoming classroom; and ultimately increase retention, particularly of underrepresented minorities including women. Herein, we discuss the development and implementation of a new hands-on freshman engineering design course, Design Practicum, with an emphasis on improvements in curriculum and teaching strategies, and creating a more inclusive environment.

\section{Development of Design Practicum}

We began by looking through student survey responses to determine areas needing improvement, and which features of past courses were the most effective at engaging students, retaining students, and creating a more inclusive environment. From there, participating faculty and our teaching intern developed curriculum and strategies to implement in our pilot course this past Fall 2016.

\section{Intro Course Student Survey}

We developed a survey with likert-scale questions and comment boxes to evaluate student opinion of classroom climate and retention of those who took and completed a freshman engineering course (department specific or multi-disciplinary) within the past three years. The survey was sent to approximately 4000 students in Spring 2016, with 992 responding. [1]

Intro Course Student Survey Results

Survey data indicates that a higher percentage of students who took one of the multi-disciplinary courses responded that they plan to stay in engineering, compared to students who took one of 
the department-specific courses. This could be due to the fact that students in a multidisciplinary course interact with students from other departments with different interests and experiences. These students discover that even if they decide they do not wish to stay in their current engineering department, there are many other potential engineering options available. When students were asked if their intro course was an important part of their first year at the College of Engineering, a higher percentage of students answered somewhat agree/strongly agree who took Intro 160 (multi-disciplinary hands-on, team-based engineering design) than any other course. General positive comments about 160 had an overall theme of excitement, fun, and friends--this could partially explain why this course was an important part of their first year.

Not surprisingly, the department-specific courses received the highest ratings in teaching valuable technical concepts and skills. Interestingly, the 160 multi-disciplinary hands-on design course had higher ratings in teaching valuable technical concepts and skills than all other multidisciplinary courses. These results are consistent with the generally accepted opinion that handson activities promote deeper learning. The past 160 course taught the engineering design process through hands-on design, where they had the opportunity to apply skills, such as shop training, computer-aided design, and basic physics. The other multi-disciplinary courses did not have a hands-on component.

Data sets filtered by gender and ethnicity were compared to determine best practices for providing an inclusive environment in the classroom. The data shows that when comparing male vs. female and URM vs. non-URM, there were no significant differences, including questions about staying in engineering, influencing educational decisions, confidence in engineering, or feeling welcome in engineering. Thus, the data collected regarding climate and inclusiveness will instead be used as a baseline for comparative analysis with the new Design Practicum course in the future.

Student negative comment data on the Intro 160 hands-on design course was used to identify the most critical areas in need of improvement. Common negative comments included: class size and teams were too large (10-15 students per team); inconsistent curriculum and homework among different sections; and inappropriate/poor design projects. These problems were directly addressed as we developed the new course, as outlined below.

\section{Implementation of Design Practicum}

The new freshman engineering design course, Design Practicum, is a 2 credit hands-on, teambased introduction to engineering design. The class meets once per week for three hours, with lecture the first hour, and lab the second two hours. Students are introduced to design via the invention, fabrication and testing of a device that solves a problem proposed by a real client. These projects cover a variety of engineering disciplines including bioinstrumentation, biomechanics, mechanical, and civil and environmental. Lectures address information retrieval techniques, specification writing, methods for enhancing creativity, analysis techniques, scheduling, selection methodologies, cost estimating, sustainability in design, shop safety, fabrication equipment and techniques, and oral and written communication. Lab time consists of team activities, shop training, and the design process--brainstorming through fabrication and testing. 
Our survey results suggest that retention rates (self-reported retention to engineering) are higher with students who took a multi-disciplinary course compared to the department-specific courses. Multi-disciplinary teams provide a more real-world example of engineering teams in industry and academia, and they also provide freshmen an opportunity to talk to students with different interests. Based on this, our survey results, and the fact that freshmen have to finalize their engineering department choice by the end of their first year, we felt strongly that freshmen would benefit more from a multi-disciplinary (different engineering disciplines) course than from a department-specific course.

\section{Design Practicum Course Improvements}

The Design Practicum course is capped at 24 students per section, with 6-8 students per team. This is a considerable improvement from the previous hands-on design course (160) which was capped at 36 students, and had large teams of 10-15 students. To address student complaints of differences among sections, instructor meetings are held weekly to continually improve curriculum and to ensure all sections are taught consistently. In an effort to make sure students have an appropriate engineering problem solving opportunity in every section, clients who are solicited to participate are given clear expectations for projects. Projects must allow engineering design, and clients must provide a budget (\$150-\$300 per team), respond to student questions throughout the semester, and attend student presentations.

\section{Inclusiveness Strategies}

This past Fall 2016, we worked with our on-campus teaching internship program and proposed a project to develop strategies to increase inclusiveness in the classroom. The intern's research revealed that providing a framework for teams that promotes inclusion, communication, respect, and responsibility is a successful strategy for building strong teams and a more inclusive classroom. [6-8] Thus, a team contract activity was developed and implemented this past fall 2016 in all sections of the new Design Practicum course. The intern also assessed students' experiences and attitudes about teams at the beginning of the semester and at the end of the semester to determine if attitudes regarding teamwork changed.

New active learning strategies were also implemented to promote inclusiveness by offering multiple teaching and learning styles. Strategies piloted this past fall include: short (10-15 minutes each) video lectures on the design process with online quizzes; online tutorials, videos, and full lectures covering content that was either not covered during class, or content that is deemed crucial in the design process. Some sections also implemented alternative forms of communication including video blogging, and weekly individual lab reflections.

\section{Conclusion}

In the next several months, we will continue to analyze and compare all student survey data from our pilot Design Practicum course. We will also distribute the student intro course survey on climate, retention, and inclusiveness to students who took Design Practicum this past Fall 2016 and this Spring 2017 and compare this data to the old 160 course. Based on survey analysis and continuing research, improvements will be made and implemented Fall 2017. Our hope is to create a welcoming, inclusive freshman engineering design experience that ultimately contributes to an increase in retention of underrepresented minorities. 


\section{References}

[1] Puccinelli, TJ, Fitzpatrick, M., Masters, G., Murphy, JG, The Evolution of the Freshman Engineering Experience to Increase Active Learning, Retention, and Diversity--Work in Progress. American Society for Engineering Education, 2016.

[2] B. M. Olds and R. L. Miller, "The effect of a first-year integrated engineering curriculum on graduation rates and student satisfaction: A longitudinal study," Journal of Engineering Education, vol. 93, p. 23, 2004.

[3] S. S. Courter, S. B. Millar, and L. Lyons, "From the students' point of view: Experiences in a freshman engineering design course," Journal of Engineering Education, vol. 87, pp. 283-288, 1998.

[4] D. W. Knight, L. E. Carlson, and J. F. Sullivan, "Staying in engineering: Impact of a hands-on, team-based, first-year projects course on student retention," age, vol. 8, p. 1, 2003.

[5] D. Kilgore, C. J. Atman, K. Yasuhara, T. J. Barker, and A. Morozov, "Considering context: A study of first-year engineering students," Journal of Engineering Education, vol. 96, p. 321, 2007.

[6] Trede, F., Macklin, R., \& Bridges, D. Professional identity development: A review of the higher education literature. Studies in Higher Education, 37(3), 365-384, 2011.

[7] M. Prince, "Does active learning work? A review of the research," Journal of Engineering Education, vol. 93, pp. 223-231, 2004.

[8] Van Wie, Bernard J., et al. "Team Building in a Project-based Learning Fluid Mechanics and Heat Transfer Course." American Society for Engineering Education. American Society for Engineering Education, 2011. 